\title{
RELATIONSHIPS BETWEEN PHENOTYPE, MATING BEHAVIOR, AND FITNESS OF QUEENS IN THE ANT LASIUS NIGER
}

\author{
Else J. FJeRdingstad ${ }^{1,2}$ And LAURent KelleR ${ }^{1}$ \\ ${ }^{1}$ Department of Ecology and Evolution, University of Lausanne, CH-1015, Lausanne, Switzerland
}

\begin{abstract}
Considerable attention has focused on why females of many species mate with several males. For social hymenopteran insects, efforts have primarily concentrated on determining whether multiple mating increases colony performance due to the increased genetic diversity. Most of these studies are correlative because it is difficult or impossible to experimentally mate queens in most species. Thus, the positive associations found between multiple paternity and colony fitness in some cases may not be due to direct effects of genetic diversity but could, in theory, arise from high-quality queens having more mates. Here we show that in the ant Lasius niger variation in the number of matings covaries with queen phenotype. Young queens that were heavier at the time of the mating flight were significantly more likely to mate with several males. As a result, heavier queens stored more sperm. The initial weight of queens was significantly associated with the probability of surviving mating flights during the two years of the study, with queens of intermediate weight having the highest across-year survival. Queen initial weight was also significantly and positively associated with the quantity of brood at the time of the first worker eclosion as well as colony productivity at the time of hibernation. By contrast, there was little evidence for a positive effect of the number of matings on colony performance when the effect of mate number and queen initial weight were considered simultaneously.
\end{abstract}

Key words._Mating frequency, natural selection, polyandry, social insects, sperm.

Received September 22, 2003. Accepted January 15, 2004.

One of the more debated issues in evolutionary biology is why females in many species mate with multiple males (polyandry). Usually a single male can supply enough sperm for fertilizing a female's batch of eggs. Moreover, mating entails costs such as time and energy costs devoted to courtship and copulation, increased risk of predation while mating, and risk of disease from parasite transmission, all of which may shorten the female's life span (Daly 1978; Thornhill and Alcock 1983; Sherman et al. 1988; Jennions and Petrie 2000). The question of why females mate multiply has raised particular interest in social Hymenoptera (ants, bees, and wasps) because the number of mates per queen affects the relatedness among nestmates and thus the expectations for conflict and cooperation within colonies (Ratnieks 1988; Pamilo 1991; Crozier and Pamilo 1996; Ratnieks and Boomsma 1997). In addition, multiple mating in the social Hymenoptera is interesting because some of the selective factors that have been proposed to favor multiple mating in insects (Arnqvist and Nilsson 2000) are unlikely to apply. Thus, there is no courtship feeding, no spermatophore, and queens store large energy reserves before their mating flight such that the transfer of nutritious substances by males is not likely to be a potential benefit promoting multiple mating (see Boomsma and Ratnieks 1996).

Several hypotheses have been put forward to account for the evolution and maintenance of multiple mating in social insects, with most of these hypotheses proposing that polyandry is advantageous because of the resultant increase in genetic variability within colonies. Increased genetic variability has been suggested to provide benefits in the form of enhanced disease resistance or increased worker force effi-

\footnotetext{
${ }^{2}$ Present address: Laboratoire d'Ecologie, CNRS UMR 7625, Université Pierre et Marie Curie, 7 Quai Saint-Bernard, Bât. A, 7ème étage, case 237, F-75252 Paris Cedex 05, France; E-mail: Else.Fjerdingstad@snv.jussieu.fr.
}

ciency (Crozier and Page 1985; Hamilton 1987; Sherman et al. 1988; Keller and Reeve 1994; Schmid-Hempel 1994, 1998; Bourke and Franks 1995; Boomsma and Ratnieks 1996; Crozier and Pamilo 1996). These hypotheses have in common that they predict an increased survival and growth of colonies with greater genetic diversity thus leading to a higher fitness of multiply mated queens.

Although theoretical advances have been considerable in the last decades, empirical tests of these hypotheses have frequently been negative, inconclusive, or inconsistent across species (Bourke and Franks 1995; Boomsma and Ratnieks 1996; Crozier and Pamilo 1996; Kraus and Page 1998; Schmid-Hempel 1998; Sherman et al. 1998; Crozier and Fjerdingstad 2001; Fjerdingstad et al. 2003; Tarpy 2003). Moreover, only few studies have experimentally manipulated the level of genetic diversity, and some of the best designed of these studies have been conducted in systems exhibiting no variability in queen mating under natural conditions (e.g., Baer and Schmid-Hempel 1999).

Interestingly, the strong emphasis by students of social insects on the potential benefits of increased genetic variability as a causal explanation of polyandry has been accompanied by an almost complete lack of attention to the role of sexual selection, which was considered unimportant due to the short duration of male-female contacts (Hölldobler and Wilson 1990). This contrasts greatly with the research tradition in nonsocial animals (Thornhill and Alcock 1983; Smith 1984; Arnqvist and Nilsson 2000; Jennions and Petrie 2000; Simmons 2001). The almost complete lack of attention on mate choice and natural and sexual selection at the individual level in social Hymenoptera is particularly striking given that in most species only a minority of queens mate multiply (Boomsma and Ratnieks 1996). Therefore, the question that needs to be addressed is actually not, "Why do queens mate multiply?" but "Why do some of the queens mate multiply and others singly?', In particular, the question 
arises as to whether variation in mating frequency might be associated with phenotypic differences among queens, and if so, whether the costs and benefits of multiple mating might covary with phenotypic characteristics of queens.

Differences in queen phenotype, particularly body weight, have been reported in many ants (e.g., Sundström 1995; Fjerdingstad and Boomsma 1997) and may have consequences for central components of queen fitness such as the ability to survive the mating flight, the probability of successful colony initiation, and the expected life span of queens and colonies. Such differences in queen fitness would, in turn, affect the value of different queens for males and could hence affect their attractiveness to males. Weight differences among queens may also correlate with the size of their spermatheca and hence with the maximum number of sperm they can store. In most social insects, queens can mate only at the beginning of their reproductive life. Therefore, the upper limit of (fertilized) eggs (offspring) she can produce is directly dependent on the numbers of sperm stored. Thus, if heavier queens can store more sperm, multiple mating may convey greater benefits for them than for lighter queens. In other words, it is possible that phenotypic differences (and particularly weight differences) among queens may influence the cost and benefit of mating multiply.

The issue of a possible association between queen phenotype and mating frequency is of additional interest because most studies that have attempted to identify the benefits of multiple mating have been correlational (i.e., correlating colony-level productivity and/or survival with queen mating frequency). Therefore, positive associations between mating frequency and colony performance may be spurious if queen mating frequency covaries with phenotypic attributes of queens that directly influence their probability of survival and/or colony productivity.

The aim of this study was to test whether queen phenotype covaries with fitness and mating behavior in ants. We chose the common European garden ant, Lasius niger, a species in which queens mate with one to four males during large-scale mating flights and the average mating frequency varies between populations and between years (van der Have et al. 1988; Boomsma and van der Have 1998; Fjerdingstad et al. 2002). Just after mating, queens initiate new colonies in small burrows in the ground where they rear the first brood on their own body reserves (Boomsma and Leusink 1981; van der Have et al. 1988; Boomsma and van der Have 1998; Fjerdingstad et al. 2002). Queens of L. niger can live up to 29 years (H. Appel in Kutter and Stumper 1969), the highest life span recorded in ants (Keller and Genoud 1997), and mature colonies can contain up to 50,000 workers (Fjerdingstad et al. 2003). The first sexuals (males and new queens) are raised when colonies are a few years old and have reached a size of approximately 4,000 workers. As in many other ants, mortality is very high during the mating flight and the stage of colony founding. Overall, only a tiny proportion of queens that are produced will be able to successfully initiate a colony and produce sexual offspring. As a result of these life-history characteristics, L. niger queens are likely to be under strong survival and fecundity selection, making this species an ideal system to test for a relationship between queen phenotype, fitness, and mating behavior.

\section{Materials And Methods}

\section{Collection of Samples and Data}

To test for survival selection on body weight during the mating flight, we collected samples of queens before and after flights in 1997 and 1998. The preflight samples represented the population of queens before selection and postflight queens after selection. The association between queen body weight and probability of surviving was tested using logistic regressions from which estimates of selection coefficients were also generated (cf. Janzen and Stern 1998). The preflight queens were trapped in tent traps placed over their natal nests just as they were leaving for their mating flight (further details in Fjerdingstad et al. 2002). Collections were made near the Biology Building on Lausanne University campus (Switzerland) in July 1997 and 1998 at a total of 23 and 33 colonies, respectively. From each colony 20 preflight queens were chosen at random and weighed on a Mettler Toledo balance (Columbus, $\mathrm{OH}$ ) accurate to $1 \mu \mathrm{g}$. Additionally, we determined the dry weight of five preflight queens per colony in 1997 and the fat content of seven to 14 preflight queens per colony in 1998 (following the method of Keller and Passera [1989] but with one additional exchange of petroleum ether).

The postflight queens were collected on the ground just after they mated and landed. In 1997 postflight queens were collected at four sites, all within a radius of $2-3 \mathrm{~km}$ of the Biology Building (in front of the Biology Building $n=8$, Swiss Federal Institute of Technology at Lausanne [EPFL] campus $n=55$, Closelet $n=89$, Renens $n=47$ ). All postflight queens were weighed immediately after collection and 84 of them were killed to determine their dry weight. The fresh weights of postflight queens differed slightly among the four collection sites $\left(F_{3,209}=3.1, P=0.03\right)$, but site explained only $4.3 \%$ of the variance. Dry weights, however, did not differ between the EPFL, Renens, and Closelet sites $\left(F_{2,80}=0.61, P=0.55\right.$; no data for the Biology Building site). In 1998, we collected and weighed another 203 postflight queens near the Biology Building.

A total of 117 of the postflight queens collected in 1997 and all of the 203 postflight queens collected in 1998 were allowed to start colonies in the laboratory, allowing us to study the relationship between weight and reproductive performance. After eclosion of the first workers, each colony was supplied with honey-water and an artificial diet (Keller et al. 1989) twice a week. After 4 months (at which time wild colonies start hibernation under natural conditions), the colonies were frozen to subsequently determine queen fresh weight, the number of males queens had mated with (see below), and the overall weight of the eggs, larvae, pupae, and workers produced. In 1998, we also recorded the date of eclosion of the first workers for each colony and weighed the queens and the brood at this date. Both in 1997 and 1998, a few queens died before the end of the experiments. Whenever possible, they were immediately frozen upon discovery and subjected to the same analyses as live queens.

The number of sperm stored in the spermatheca by the queens that were allowed to initiate colonies in the laboratory was determined after colony termination by dissecting out the sperm in a buffered saline solution containing $5 \%$ bovine serum albumin (Reichardt and Wheeler 1995). The sperm 
were disentangled through gentle grinding with a Teflonheaded homogenisator stick in $500 \mu \mathrm{PBS} / 5 \%$ BSA buffer. After disentangling the sperm and adding $1000 \mu 1$ more PBS buffer, the suspension was vortexed gently for $15 \mathrm{sec}$ and an equal volume of $6 \%$ paraformaldehyde was added to prevent biodegradation. The sperm suspensions were then stored at $5^{\circ} \mathrm{C}$. Estimates of the number of sperm stored by each queen were made by vortexing each sperm suspension, placing an aliquot of $40 \mu \mathrm{l}$ on a Burker-Turk cell count chamber (Karl Hecht, Sondheim, Germany) and counting the sperm using a microscope with phase contrast and $400 \times$ magnification (Fjerdingstad and Boomsma 1997).

The number of males with which the laboratory queens had mated was estimated through microsatellite analyses (two loci, LN10-53 and LN10-28; Fjerdingstad et al. 2003) of the sperm in the spermatheca. Because Hymenopteran males are haploid, the number of alleles found in each spermathecal polymerase chain reaction (PCR) provides a direct estimate of the number of mates. Due to the very high number of alleles at the two loci used (Fjerdingstad et al., 2002, 2003) the risk of two males having the same genotype was very small (less than 1\%; Fjerdingstad et al. 2003). Moreover, there was only a low risk that the alleles of the minority male (the one contributing fewer sperm than the other mate[s] of a given queen) were outcompeted in the PCRs (and hence not detected; Gertsch and Fjerdingstad 1997). This is because paternity skew in the studied population is moderate (on average, minority males sired $29 \%$ of the offspring in doublepaternity colonies; result from microsatellite based analyses of 20 female offspring per colony for 28 colonies).

In 1998 most of the sperm extractions were accidentally contaminated with one or both of the original microsatellite clones and hence also showed the clone bands on the autoradiograms. Because the concentrated clone could have outcompeted some sperm alleles in the PCR (Gertsch and Fjerdingstad 1997), making truly multiply mated queens appear singly mated, we verified the number of mates for apparently single mated queens by assessing the genotypes of eight workers per colony. In analyses using mating frequency as a variable, we used only queens for which we had unambiguous data on the number of mates for both marker loci. Mating frequency was analyzed as a bivariate variable, dividing queens into singly and multiply mated queens.

We used two approaches to investigate the effect of queen weight and mating frequency on the number of sperm stored, the time to eclosion of the first worker, and brood mass. First, we tested for the effect of each variable separately. Next we determined their partial effects by controlling each statistically for the effect of the other variable (Lande and Arnold 1983; Arnold and Wade 1984; for partial regression analysis see also Sokal and Rohlf 1995). This allowed us to investigate whether queen weight and mate number were confounded in their effects on colony performance and the reproductive potential of queens.

We used parametric statistics whenever the requisite assumptions were fulfilled. Otherwise, we used Legendre's (1999) permutation test for multiple linear regression (9999 permutations). All tests are two-tailed.
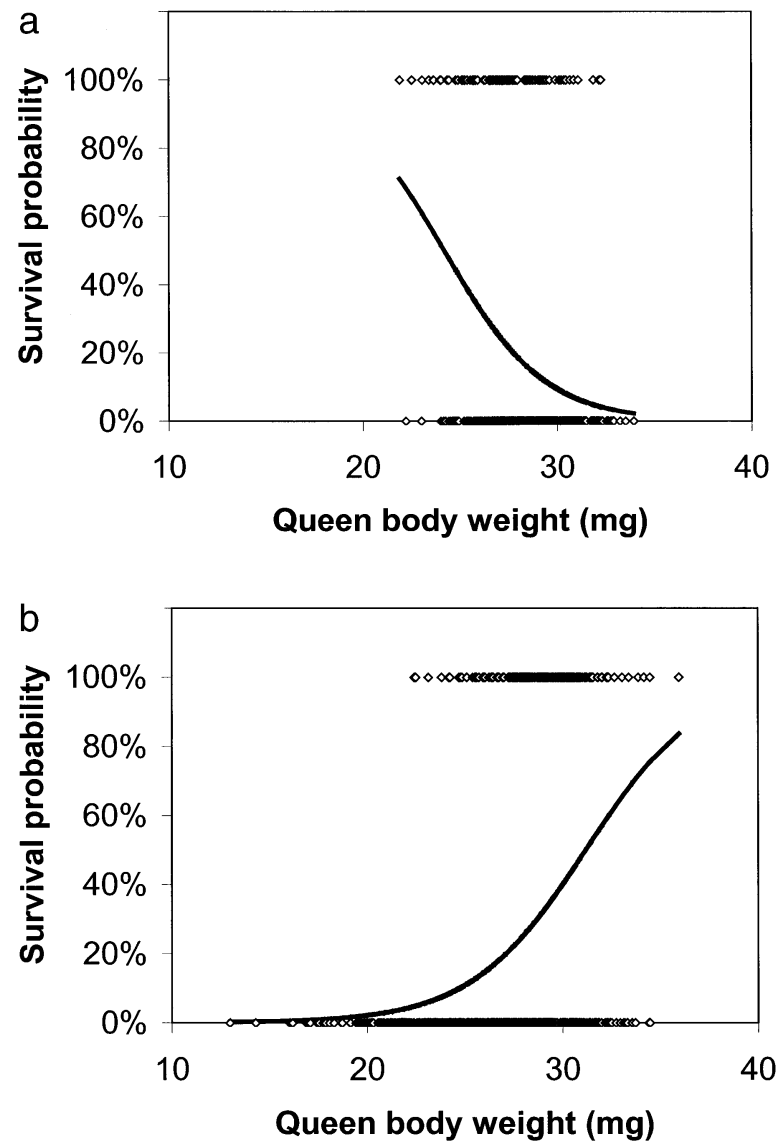

FIG. 1. Survival during the mating flight as a function of the body weight of queens. Shown are the probabilities of surviving (estimated through logistic regression analyses) and the raw data of body weights of individual queens collected before and after flights in (a) 1997 and (b) 1998.

\section{RESULTS}

\section{Queen Weight and Survival and Body Condition}

Queen body weight was significantly associated with survival probability both in 1997 and 1998. In 1997 the weight of queens collected after the mating flight (mean \pm SD: 27.3 $\pm 2.2 \mathrm{mg}, n=115$ ) was significantly lower than the weight of queens collected before the mating flight $(28.8 \pm 1.9 \mathrm{mg}$, $n=525 ;$ Wald $=49.0, \mathrm{df}=1, P<0.0001$; standardized selection coefficient, $\beta=-0.60$; Fig. 1a). The lower weight of queens collected just after the mating flight was not simply due to a loss of water during the mating flight because their dry weight (mean $\pm \mathrm{SD}$ : $15.4 \pm 1.2 \mathrm{mg}$ ) was also significantly lower than that of the queens collected before the mating flight $\left(16.0 \pm 1.3 \mathrm{mg} ; t_{188}=-3.5, P=0.0006\right)$. Also, the slight body weight differences among queens from different areas (see Materials and Methods) could not account for the difference observed because postflight queens from all sites were significantly lighter than preflight queens (oneway ANOVAs, $P<0.0005$ for all tests). Thus, lightweight queens were more likely to survive the mating flight in 1997. In 1998 , by contrast, the queens collected after the mating flight were significantly heavier $(29.0 \pm 2.3 \mathrm{mg}, n=202)$ than those collected before $(25.9 \pm 3.4 \mathrm{mg}, n=634$; Wald 
$=104.8, \mathrm{df}=1, P<0.0001 ;$ standardized selection coefficient, $\beta=0.76$; Fig. 1b), suggesting that heavier queens were more likely to survive their mating flight in that year. Both pre- and postflight queens were heavier in 1998 than 1997. The difference was $11 \%$ for preflight queens $\left(t_{1027}=\right.$ $18.3, P<0.0005)$ and $6 \%$ for postflight queens $\left(t_{315}=6.56\right.$, $P<0.0005)$. The fat-content analyses indicated that body weights of preflight queens were significantly positively associated with both the absolute (standardized regression coefficient, $\left.\beta=0.92, t_{304}=39.7, P<0.005\right)$ and relative amount of fat $\left(\beta=0.80, t_{304}=23.1, \mathrm{P}<0.0005\right)$.

\section{Queen Weight, Mating Frequency, and Reproductive Performance}

Twenty-four of the 318 postflight queens that were placed in nests died before the eclosion of the first brood. Another 10 queens produced brood that did not give rise to adult workers. There were no significant differences in the initial weight of queens that survived and successfully produced workers and queens that failed to do so (mean \pm SD and one-way ANOVAs: 1997, successful: $27.3 \pm 2.1 \mathrm{mg}$, dead: $27.2 \pm 2.4 \mathrm{mg}, F_{1,113}=0.01, P=0.93 ; 1998$, successful: $29.1 \pm 2.1 \mathrm{mg}$, dead: $28.4 \pm 3.2 \mathrm{mg}$, failures: $27.7 \pm 3.0$ $\left.\mathrm{mg}, F_{2,199}=2.0, P=0.13\right)$.

The time to eclosion of the first workers (mean number of days \pm SD: $59.5 \pm 2.02$; data for 1998 only) was not significantly associated with the initial weight of queens (standardized regression coefficient, $\beta=-0.09, t_{125}=-1.02, P$ $=0.31)$ or with the number of mates per queen $(\beta=0.02$, $\left.t_{125}=0.27, P=0.79\right)$. The variance in time of the first eclosion was also not associated with the number of mates per queen (variance for singly and multiply paternity colonies 4.4 days $^{2}$ and 4.0 days $^{2}$, respectively; Levene's test, $L=$ 0.14 , df $=1,125, P=0.71)$. Colonies headed by initially heavier queens contained more brood (mean \pm SD: $10.3 \pm$ $\left.3.10 \mathrm{mg}, \beta=0.27, t_{126}=3.1, P=0.002\right)$ than did colonies with initially lighter queens. Brood mass was, however, not associated with the number of mates per queen $(\beta=-0.13$, $\left.t_{126}=-1.4 ; P=0.15\right)$. When the effects of queen weight and number of mates per queen were controlled statistically for each other, queen weight remained significantly positively associated with brood mass $\left(\beta=0.29, t_{125}=3.4, P=0.001\right)$. The association between mate number and overall brood mass, however, became significantly negative $(\beta=-0.17$, $\left.t_{125}, P<0.05\right)$.

Four months after colony initiation brood mass was still positively associated with initial queen weight (data from 1997 and 1998 analyzed together; mean \pm SD: $28.5 \pm 2.31$ mg, ANCOVA: $F_{1,202 \text { queen-weight }}=10.3, \beta=0.24, P=0.002$, Fig. 2; no differences between years: $F_{1,202 \text { year }}=1.3, P=$ $0.26)$. By contrast, the number of mates per queen was unrelated with the overall quantity of brood (ANCOVA: $F_{1,202 \text { mates }}=0.37, \beta=0.07, P=0.37 ; F_{1,202 \text { year }}=0.75, P$ $=0.75)$. Considering simultaneously initial queen weight and number of mates in the same analysis had no major effect. Queen initial weight remained significantly associated with brood mass (ANCOVA: $F_{1,201 \text { queen-weight }}=10.3, \beta=0.23$, $\left.P=0.002 ; F_{1,201 \text { year }}=1.4, P=0.23\right)$, and there was no significant association between the number of mates and

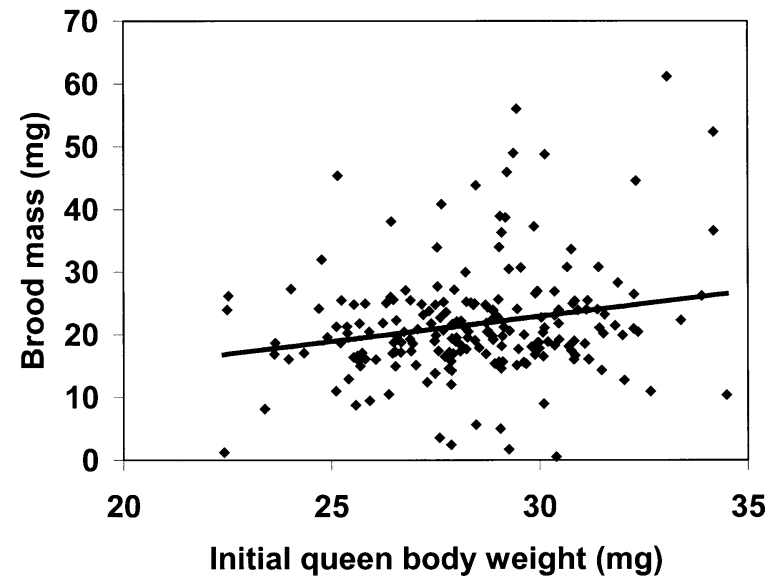

FIG. 2. Reproductive performance by queens (estimated as brood mass 4 months after colony initiation) in relation to their body weight. Data were pooled over 1997 and 1998 because there was no significant year effect (standardized regression coefficient $\beta=$ $0.24, P=0.002$; see text for details).

brood mass (ANCOVA: $F_{1,201 \text { mates }}=0.01, \beta=0.03, P=$ $0.66)$.

The number of mates per queens was positively associated with the initial body weight of queens (Fig. 3), and this association was even stronger if queens were divided into singly, doubly, triply, and quadruply mated queens (instead of just singly and multiply mated; $F_{1,222 \text { queenweight }}=9.0, \beta=$ $\left.0.19, P=0.003 ; F_{1,122 \text { year }}=36.7, P<0.0005\right)$. Also, the number of sperm obtained by a queen was significantly positively associated with her initial weight $\left(\beta=0.23, t_{133}=\right.$ $2.8, P=0.006)$. Importantly, however, this latter association became nonsignificant when the number of mates per queen was also considered in the analysis $\left(\beta=0.14, t_{132}=1.7, P\right.$ $=0.09)$. Thus, only the number of mates explained a significant part of the variation in sperm content $\left(\beta=0.38, t_{132}\right.$ $=4.6, P<0.0005)$ with multiply mated queens having $33 \%$ more sperm $(6.1 \pm 1.46[\mathrm{SD}]$ million $)$ than single-mated queens (4.6 \pm 1.81 million; Fig. 4$)$.

\section{DisCUSSION}

The first interesting finding of this study is that a queen's probability to survive her mating flight is strongly associated with her body weight. The direction of survival selection was positively associated with queen initial (fresh and dry) weight in 1998 and negatively so in 1997. This difference between years in part results from the among-year difference in the mean weight of preflight queens. Preflight queens were significantly heavier in 1997 than in 1998, possibly because of year-to-year variation in the amount of resources available (Rosenheim et al. 1996; Ode and Rissing 2002). Also, the direction of selection changed slightly across years, possibly due to year-to-year variation in the strength of the selective factors affecting survival during the mating flight (e.g., the type and prevalence of birds and other predators). Overall, our data indicate that queens with a medium body weight have the highest survival probability across years.

The initial weight of $L$. niger queens also influenced colony productivity. Larger queens produced more brood than did 


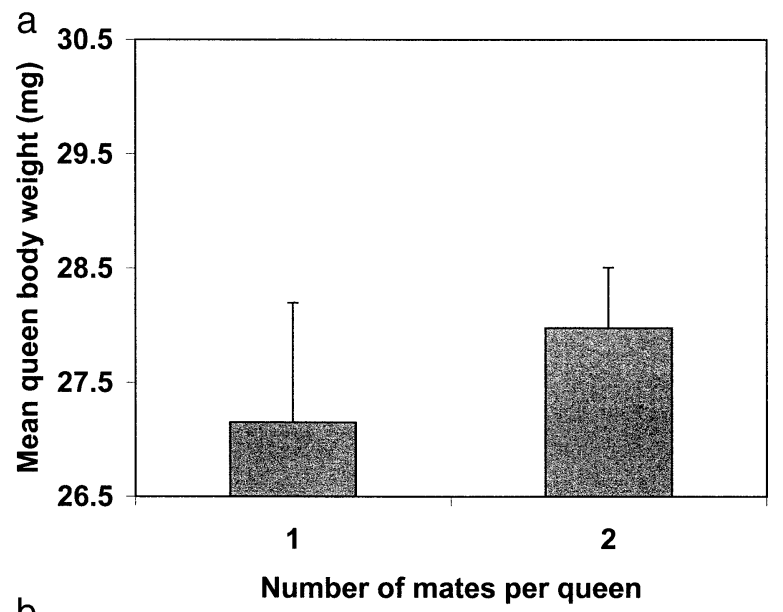

b

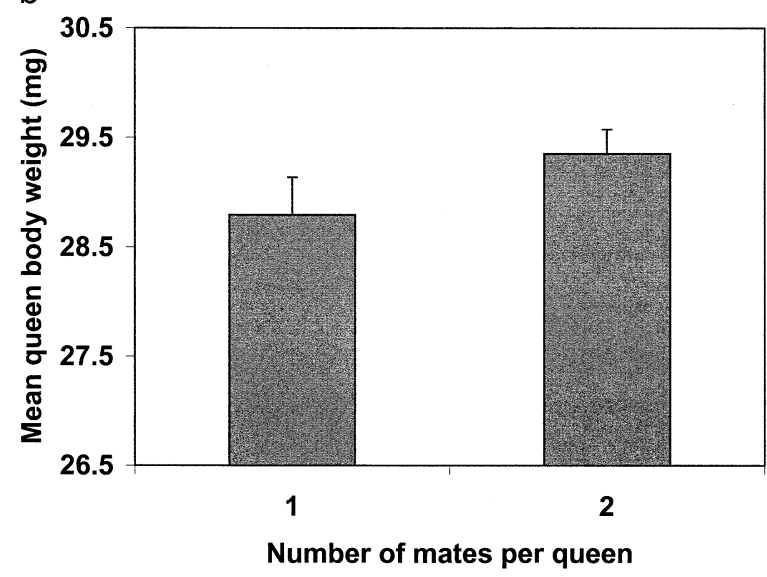

FIG. 3. Number of mates per queen in relation to queen body weight in (a) 1997 (81 singly mated and 17 multiply mated queens examined) and (b) 1998 (45 and 82 queens examined, respectively; standard errors of mean body weight shown). Heavier queens had more mates (data for both years analyzed together in an ANCOVA, $F_{1,222 \text { queenweight }}=4.0, \beta=0.13 ; P<0.05 ; F_{1,222 \text { year }}=43.2, P<$ $0.0005)$. The association between queen body weight and number of mates was much stronger if queens were divided into singly, doubly, triply, and quadruply mated queens (see text). Values on the $\mathrm{x}$-axes indicate queens with one or at least two mates.

smaller queens both when measured at the time of eclosion of the first workers and at the beginning of hibernation (autumn). The greater productivity of colonies headed by heavier queens most likely resulted from these queens having more energy stores to raise the first brood. In L. niger, as in most other independent-colony-founding species, queens raise the first brood by metabolizing their wing muscles and using their fat reserves (Keller and Passera 1989), and our fat content analyses indeed revealed that heavier queens had both a higher absolute and relative fat content than lighter queens. A positive association between body weight and fat stores has also been found in other ants (Keller and Ross 1993; McInnes and Tschinkel 1995; Sundström 1995; Lachaud et al. 1999) and differences in initial weight have been shown to influence various estimators of queen productivity in several species (Vander-Meer et al. 1992; Bernasconi and Keller 1999; Wagner and Gordon 1999; Liu et al. 2001; DeHeer 2002; see also Tschinkel 1993).

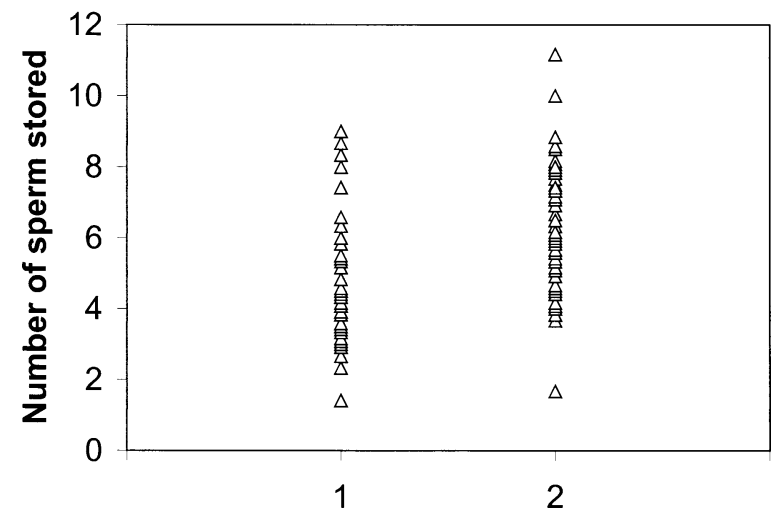

Number of mates per queen

FIG. 4. Number of sperm stored by queens as a function of the number of mates per queens. Queens stored more sperm when they had more mates (standardized regression coefficient $\beta=0.42, t_{132}$ $=5.3, P<0.0001)$. Values on the $\mathrm{x}$-axis indicate queens with one or at least two mates.

Variation between colonies in brood mass is likely to translate into significant fitness variation because in species with independent colony founding, large colonies often eradicate smaller neighboring colonies during the first year following colony founding (Tschinkel 1992; Sommer and Hölldobler 1995; but see Gordon and Kulig 1998). Hence, even small differences in early colony growth may translate into very large differences in lifetime reproductive success.

Another interesting finding of this study is that the weight of $L$. niger queens at the time of the mating flight was significantly positively associated with the number of males they mated with. There are at least four possible explanations for this association. The first is that heavier queens can store more sperm and thus would benefit more from mating with several males (cf. Cole 1983; Tschinkel 1987; Fjerdingstad and Boomsma 1998). However, our data showed that the number of sperm stored was not significantly associated with queen initial weight when the number of matings was controlled for, suggesting that queen size differences may not significantly influence the number of sperm that queens can store.

A second possible explanation is that the cost of mating with several males is smaller for heavier queens. The main cost associated with multiple mating is probably the greater time spent in the air (Reichardt and Wheeler 1996) and thus greater predation pressure. Our study showed that heavier queens possess greater energy reserves, but there was no evidence that heavier queens consistently had a greater survival during the mating flight. It therefore remains unclear whether mating multiply is less costly for heavier queens.

A third possibility is that heavier females are more attractive to males. Male preference for females of high quality has been reported in a large number of insects and other animals (Parker 1983; Owens and Thompson 1994; Johnstone et al. 1996; Johnstone 1997; Bonduriansky 2001). In ants, a possible additional reason for male choosiness (Dewsbury 1982 ) is that males are sperm-limited as a result of the testes degenerating during the larval stage (Hölldobler and Wilson 1990, pp. 154-155). However, in our L. niger population the 
initial numerical sex ratio is strongly male biased (from 6.1:1 to $6.6: 1$; Fjerdingstad et al. 2001, unpubl. data), so that males that reject a low-quality queen may not obtain another mating opportunity (but see Bonduriansky and Brooks 1999; Bonduriansky 2001).

A final possible explanation for the positive association between queen body weight and mating frequency is that queens are forced to mate multiply, and heavier queens are less likely to prevent additional males from mating with them. Under this hypothesis, multiple mating would not confer any advantages on queens. Consistent with this hypothesis, the present study as well as another study that examined 113 mature L. niger natural colonies (Fjerdingstad et al. 2003) failed to find any consistent benefits of multiple mating in terms of colony performance (though a lack of benefits cannot prove the hypothesis of coercive matings).

It is important to note that the four hypotheses mentioned above are not mutually exclusive. Whatever the cause(s) underlying the fact that heavier queens have more matings, this association has important implications for studies aimed at assessing the potential benefits for queens that mate with several mates. In most previous studies comparing the performance of colonies headed by singly versus multiply mated queens, queen body weight variation was not taken into account. Experimental manipulation of the number of mates per queen has been performed only in the honeybee and bumblebees. For the honeybee some studies have found a positive effect between mating frequency and colony performance (Oldroyd et al. 1992; Fuchs and Schade 1994; Tarpy 2003), while others have found no effect (Page et al. 1995; Fuchs et al. 1996; Kraus and Page 1998; Neumann and Moritz 2000). In Bombus terrestris, colonies headed by queens mated with several unrelated males showed greater productivity than colonies headed by several related males (Baer and Schmid-Hempel 1999, 2000). However, in this species queens usually mate once (Schmid-Hempel and SchmidHempel 2000) and colonies headed by singly mated queens show greater colony productivity than colonies headed by several related males. Thus, the reasons why queens mate multiply in honeybees and singly in bumblebees are still not completely clear.

In ants experimental studies on the effect of multiple mating on colony productivity have not been possible because, so far, it has been impossible to experimentally control the number of matings (queens usually only mate on the wing during a mating flight far from human manipulators). A significant association between colony performance and colony genetic diversity has been reported in a single ant species, the harvester ant Pogonomyrmex occidentalis (Cole and Wiernasz 1999). However, factors others than mating frequency may have influenced the genetic diversity of workers in this species. For example, more productive colonies may have contained several queens (Fjerdingstad and Keller 2000) and/ or may have raided other colonies and thus coincidentally acquired a greater genetic diversity of workers (Gadau et al. 2003). Moreover, it is also possible that the number of matings is correlated with initial queen body weight, as in $L$. niger. Therefore the positive association found between intracolonial genetic diversity and colony growth and survival possibly may have resulted from high-quality queens having more mates. Our study on L. niger exemplifies that the association between the number of mates per queen and colony performance may change when controlling for the initial body weight of queens. Thus, the negative association between mate number and brood mass at the time of eclosion of the first worker was significant only when the initial weight of the queen was controlled for.

It is not clear why, at the time of the first worker eclosion, mate number was negatively associated with overall brood mass (when initial queen weight was controlled for). One possibility is that queens with multiple mates produce fewer eggs and that their broods experience a slower development at the larval stage, perhaps due to deleterious substances transmitted by males as part of a male-male conflict over fertilization (cf. Chapman et al. 1995). Alternatively, components of queen phenotype other than initial weight may be associated with mate number, hence resulting in the observed (noncausal) relationship between mate number and brood mass. Whatever the cause, our data show that differences in queen mating frequency can be associated with phenotypic differences that may also influence colony productivity.

In summary, our study shows that the initial weight of $L$. niger queens affects the probability of surviving the mating flight and the productivity of new colonies during their first months. This is likely to translate into significant differences in the lifetime reproductive success of queens. Initial weight of queens was also positively associated with the probability that queens mate with several males. As a result, the association between number of mates and brood mass at the time of eclosion of the first workers changed when the analysis was controlled for the effect of initial queen weight. Overall there was little evidence that mating with several males had a positive effect on colony performance once queen initial weight was controlled for. Hence, it is necessary to consider simultaneously the effect of mate number and queen quality when studying the potential benefits of multiple mating in social insects.

\section{ACKNOWLEDGMENTS}

We thank F. Balloux, M. Krieger, D. Molbo, G. l'Hoste, and M. Reuter for help in the field; I. Hoznour, M. Ménétrey, A.-M. Mehmeti, B. Pavillard, and C. Roger for help in the laboratory; and W. Blanckenhorn, W. Brown, M. Chapuisat, C. Doums, A.A. Hoffmann, T. Tregenza, and two anonymous reviewers for constructive comments on earlier versions of this paper. EJF was supported by postdoctoral grants from the Carlsberg Foundation, Denmark, and LK by grants from the Swiss National Science Foundation.

\section{Literature Cited}

Arnold, S. J., and M. J. Wade. 1984. On the measurement of natural and sexual selection: theory. Evolution 38:709-719.

Arnqvist, G., and T. Nilsson. 2000. The evolution of polyandry: multiple mating and female fitness in insects. Anim. Behav. 60: $145-164$

Baer, B., and P. Schmid-Hempel. 1999. Experimental variation in polyandry affects parasite loads and fitness in a bumble-bee. Nature 397:151-154.

- 2001. Unexpected consequences of polyandry for parasitism and fitness in the bumblebee Bombus terrestris. Evolution 55:1639-1643. 
Bernasconi, G., and L. Keller. 1999. Effect of queen phenotype and social environment on early queen mortality in incipient colonies of the fire ant, Solenopsis invicta. Anim. Behav. 57:371-377.

Bonduriansky, R. 2001. The evolution of male mate choice in insects: a synthesis of ideas and evidence. Biol. Rev. 76:305-339.

Bonduriansky, R., and R. J. Brooks. 1999. Why do male antler flies (Protopiophila litigata) fight? The role of male combat in the structure of mating aggregations on moose antlers. Ethol. Ecol. Evol. 11:287-301.

Boomsma, J. J., and A. Leusink. 1981. Weather conditions during nuptial flights of four European ant species. Oecologia 50: 236-241.

Boomsma, J. J., and F. L. W. Ratnieks. 1996. Paternity in eusocial Hymenoptera. Philos. Trans. R. Soc. Lond. B 351:947-975.

Boomsma, J. J., and T. M. Van der Have. 1998. Queen mating and paternity variation in the ant Lasius niger. Mol. Ecol. 7: 1709-1718.

Bourke, A. F. G., and N. R. Franks. 1995. Social evolution in ants. Princeton Univ. Press, Princeton, NJ.

Chapman, T., L. F. Liddle, J. M. Kalb, M. F. Wolfner, and L. Partridge. 1995. Cost of mating in Drosophila melanogaster females is mediated by male accessory gland products. Nature 373 : 241-244.

Cole, B. J. 1983. Multiple mating and the evolution of social behaviour in the Hymenoptera. Behav. Ecol. Sociobiol. 12: $191-201$

Cole, B. J., and D. C. Wiernasz. 1999. The selective advantage of low relatedness. Science 285:891-893.

Crozier, R. H., and E. J. Fjerdingstad. 2001. Polyandry in social Hymenoptera: Disunity in diversity? Ann. Zool. Fenn. 38: 267-285

Crozier, R. H., and R. E. Page. 1985. On being the right size: male contributions and multiple mating in social Hymenoptera. Behav. Ecol. Sociobiol. 18:105-115.

Crozier, R. H., and P. Pamilo. 1996. Evolution of social insect colonies: sex allocation and kin selection. Oxford Univ. Press, Oxford, U.K.

Daly, M. 1978. The cost of mating. Am. Nat. 112:771-774.

DeHeer, C. J. 2002. A comparison of the colony-founding potential of queens from single- and multiple-queen colonies of the fire ant Solenopsis invicta. Anim. Behav. 64:655-661.

Dewsbury, D. A. 1982. Ejaculate cost and male choice. Am. Nat. 199:601-610.

Fjerdingstad, E. J., and J. J. Boomsma. 1997. Variation in size and sperm content of sexuals in the leafcutter ant Atta colombica. Insectes Soc. 44:209-218.

- 1998. Multiple mating increases the sperm stores of Atta colombica leafcutter ant queens. Behav. Ecol. Sociobiol. 42: 257-261

Fjerdingstad, E. J., and L. Keller. 2000. The nature of ant colony success. Science 287:1363b. Full article available online at http://www.sciencemag.org/cgi/content/full/287/5457/1363b.

Fjerdingstad, E. J., P. J. Gertsch, and L. Keller. 2002. Why do some social insect queens mate with several males? Testing the sex ratio manipulation hypothesis in Lasius niger. Evolution 56 : $553-562$

2003. The relationship between multiple mating by queens, within-colony genetic variability and fitness in the ant Lasius niger. J. Evol. Biol. 16:844-853.

Fuchs, S., and V. Schade. 1994. Lower performance in honeybee colonies of uniform paternity. Apidologie 25:155-168.

Fuchs, S., R. Büchler, S. Hoffmann, and K. Bienefeld. 1996. Nonadditive colony performances by inseminating queens with mixed sperm of several carniolan breeder lines. Apidologie 27: 304-306

Gadau, J., C. P. Strehl, J. Oettler, and B. Hölldobler. 2003. Determinants of intracolonial relatedness in Pogonomyrmex rugosus (Hymenoptera: Formicidae): mating frequency and brood raids. Mol. Ecol. 12:1931-1938.

Gertsch, P. J., and E. J. Fjerdingstad. 1997. Biased amplification and the utility of spermatheca-PCR for mating frequency studies in Hymenoptera. Hereditas 126:183-186.

Gordon, D. M., and A. Kulig. 1998. The effect of neighbours on the mortality of harvester ant colonies. J. Anim. Ecol. 67 $141-148$.

Hamilton, W. D. 1987. Kinship, recognition, disease, and intelligence: constraints of social evolution. Pp. 81-102 in Y. Itô, J. L. Brown, and J. Kikkawa. Japanese Science Society Press, Tokyo.

Hölldobler, B., and E. O. Wilson. 1990. The ants. Springer-Verlag, Berlin.

Janzen, F. J., and H. S. Stern. 1998. Logistic regression for empirical studies of multivariate selection. Evolution 52:1564-1571.

Jennions, M. D., and M. Petrie. 2000. Why do females mate multiply? A review of the genetic benefits. Biol. Rev. 75:21-64.

Johnstone, R. A. 1997. The tactics of mutual mate choice and competitive search. Behav. Ecol. Sociobiol. 40:51-59.

Johnstone, R. A., J. D. Reynolds, and J. C. Deutsch. 1996. Mutual mate choice and sex differences in choosiness. Evolution 50: 1382-1391.

Keller, L., and M. Genoud. 1997. Extraordinary lifespans in ants: a test of evolutionary theories of ageing. Nature 389:958-960.

Keller, L., and L. Passera. 1989. Size and fat content of gynes in relation with the mode of colony founding in ants (Hymenoptera; Formicidae). Oecologia 80:236-240.

Keller, L., and H. K. Reeve. 1994. Genetic variability, queen number, and polyandry in social Hymenoptera. Evolution 48 694-704.

Keller, L., and K. G. Ross. 1993. Phenotypic plasticity and "cultural transmission" of alternative social organizations in the fire ant, Solenopsis invicta. Behav. Ecol. Sociobiol. 33:121-129.

Keller, L., D. Cherix, and P. Ulloa-Chacon. 1989. Description of a new artificial diet for rearing ant colonies as Iridomyrmex humilis, Monomorium pharaonis and Wasmannia auropunctata $(\mathrm{Hy}-$ menoptera, Formicidae). Insectes Soc. 36:348-352.

Kraus, B., and R. E. Page. 1998. Parasites, pathogens and polyandry in social insects. Am. Nat. 151:383-391.

Kutter, H., and R. Stumper. 1969. Herman Appel, ein leidgeadelter Entomologie (1892-1966). Pp. 275-279 in Proceedings of the 6th international congress of the International Union for the Study of Social Insects, Bern.

Lachaud, J.-P., A. Cadena, B. Schatz, G. Pérez-Lachaud, and G. Ibarra-Nùnez. 1999. Queen dimorphism and reproductive capacity in the ponerine ant, Ectatomma ruidum Roger. Oecologia 120:515-523.

Lande, R., and S. J. Arnold. 1983. The measurement of selection on correlated characters. Evolution 37:1210-1226.

Legendre, P. 1999. Multiple linear regression permutation tests. Université de Montréal, Canada. Available via http://www.fas. umontreal.ca/biol/legendre.

Liu, Z., S. Yamane, J.-I. Kojima, Q. Wang, and S. Tanaka. 2001. Flexibility of first brood production in a claustral ant, Camponotus japonicus (Hymenoptera: Formicidae). J. Ethol. 19:87-91.

McInnes, D. A., and W. R. Tschinkel. 1995. Queen dimorphism and reproductive strategies in the fire ant Solenopsis geminata $(\mathrm{Hy}-$ menoptera, Formicidae). Behav. Ecol. Sociobiol. 36:367-375.

Neumann, P., and R. F. A. Moritz. 2000. Testing genetic variance hypotheses for the evolution of polyandry in the honeybee (Apis mellifera L.). Insectes. Soc. 47:271-279.

Ode, P. J., and S. W. Rissing. 2002. Resource abundance and sex allocation by queen and workers in the harvester ant, Messor pergandei. Behav. Ecol. Sociobiol. 51:548-556.

Oldroyd, B. P., T. E. Rinderer, J. R. Harbo, and S. M. Buco. 1992 Effects of intracolonial genetic diversity on honey bee (Hymenoptera: Apidae) colony performance. Ann. Entomol. Soc. Am. 85:335-343.

Owens, I. P. F., and D. B. A. Thompson. 1994. Sex differences, sex ratios and sex roles. Proc. R. Soc. Lond. B 258:93-99.

Page, R. E., G. E. Robinson, M. K. Fondrk, and M. E. Nasr. 1995. Effects of worker genotypic diversity on honey bee colony development and behavior (Apis mellifera L.). Behav. Ecol. Sociobiol. 36:387-396.

Pamilo, P. 1991. The evolution of colony characteristics in social insects. II. Number of reproductive individuals. Am. Nat. 138: $412-433$

Parker, G. A. 1983. Mate quality and mating decisions. Pp. 141- 
166 in P. Bateson, ed. Mate choice. Cambridge Univ. Press, New York.

Ratnieks, F. L. W. 1988. Reproductive harmony via mutual policing by workers in eusocial Hymenoptera. Am. Nat. 132:217-236.

Ratnieks, F. L. W., and J. J. Boomsma. 1997. On the robustness of split sex ratio predictions in monogynous social Hymenoptera. J. Theor. Biol. 185:423-439.

Reichardt, A. K., and D. E. Wheeler. 1995. Estimation of sperm numbers in insects by fluorometry. Insectes Soc. 42:449-452.

. 1996. Multiple mating in the ant Acromyrmex versicolor: a case of female control. Behav. Ecol. Sociobiol. 38:219-225.

Rosenheim, J. A., P. Nonacs, and M. Mangel. 1996. Sex ratios and multi-faceted parental investment. Am. Nat. 148:501-535.

Schmid-Hempel, P. 1994. Infection and colony variability in social insects. Philos. Trans. R. Soc. Lond. B 346:313-321.

. 1998. Parasites in social insects. Princeton Univ. Press, Princeton, NJ

Schmid-Hempel, R., and P. Schmid-Hempel. 2000. Female mating frequencies in Bombus spp. from Central Europe. Insectes Soc. 47:36-41.

Sherman, P. W., T. D. Seeley, and H. K. Reeve. 1988. Parasites, pathogens, and polyandry in social Hymenoptera. Am. Nat. 131: 602-610.

Simmons, L. W. 2001. Sperm competition and its evolutionary consequences in the insects. Princeton Univ. Press, Princeton, NJ.

Sokal, R., and F. J. Rohlf. 1995. Biometry. W. H. Freeman and Co., New York.
Sommer, K., and B. Hölldobler. 1995. Colony founding by queen associations and determinants of reduction in queen number in the ant Lasius niger. Anim. Behav. 50:287-294.

Sundström, L. 1995. Dispersal polymorphism and physiological conditions of males and females in the ant Formica truncorum. Behav. Ecol. 6:132-139.

Tarpy, D. R. 2003. Genetic diversity within honeybee colonies prevents severe infections and promotes colony growth. Proc. R. Soc. Lond. B 270:99-103.

Tschinkel, W. R. 1987. Fire ant queen longevity and age: estimation by sperm depletion. Ann. Entomol. Soc. Am. 80:263-266.

. 1992. Brood raiding and the population dynamics of founding and incipient colonies of the fire ant, Solenopsis invicta. Ecol. Entomol. 17:179-188.

. 1993. Resource allocation, brood production and cannibalism during colony founding in the fire ant, Solenopsis invicta. Behav. Ecol. Sociobiol. 33:209-223.

Van der Have, T. M., J. J. Boomsma, and S. B. J. Menken. 1988. Sex investment ratios and relatedness in the monogynous ant Lasius niger (L.). Evolution 42:160-172.

Vander-Meer, R. K., L. Morel, and C. S. Lofgren. 1992. A comparison of oviposition rates from monogynes and polygyne fire ants, Solenopsis invicta. Physiol. Entomol. 17:384-390.

Wagner, D., and D. M. Gordon. 1999. Colony age, neighborhood density and reproductive potential in harvester ants. Oecologia 119:175-182.

Corresponding Editor: T. Tregenza 